\title{
Conceptualizing the Consumer of Financial Services: a New Approach?
}

\author{
Lorna Fox O’Mahony ${ }^{1}$ - Christian Twigg-Flesner ${ }^{2}$ • \\ Folarin Akinbami ${ }^{3}$
}

Received: 28 April 2015 / Accepted: 29 April 2015/

Published online: 10 May 2015

(C) Springer Science+Business Media New York 2015

\section{Background}

The Financial Services Act 2012 ushered in a new era in the regulation of UK financial services. The institutional structure of financial regulation was over-hauled, and the responsibility for the protecting users (consumers) of financial services was transferred from the Financial Services Authority FSA to a new regulator, the Financial Conduct Authority (FCA). At the same time, the FCA has also taken over the responsibility for the regulation of consumer credit from the Office of Fair Trading (OFT). It is therefore an opportune moment to reflect on how the authors think of the "consumer" of financial services and therefore how best to protect this consumer.

The 2012 Act has made "ensuring that the relevant markets function well" the core objective of the FCA, with "consumer protection" one of three operational objectives (s6(1B)). This Special Issue aims to explore the implications of the Act, and the constitution of the new FCA, for the delivery of consumer protection for users of retail financial services. Key questions include how we conceptualize, and identify, "vulnerable" consumers (or vulnerable groups of consumers), how we understand and protect consumers across a "differentiated" population, and how we conceive of, design, and target financial services regulation to support better outcomes for consumers.

Christian Twigg-Flesner

c.twigg-flesner@hull.ac.uk

Lorna Fox O’Mahony

lfox@essex.ac.uk

Folarin Akinbami

folarin.akinbami@jpmchase.com

1 University of Essex, Wivenhoe Park, Colchester CO4 3SQ, UK

2 Journal of Consumer Policy, Law School, University of Hull, Hull HU6 7RX, UK

3 Durham Law School, Durham University, Durham DH1 3LE, UK 
The policy discourse surrounding the new, post-crisis landscape of consumer protection has alternated between themes of strengthening consumer protection, concerns about mis-selling, and acknowledgement of the heterogeneity of consumers, on the one hand, tempered by the resilient language of consumer responsibility and a re-emphasis on information disclosure to enable consumers to avoid risks and protect themselves, on the other. The aim of this Special Issue is to explore the legal subjectivity of financial services consumers under the new arrangements. The contributions explore the potential impacts of the Act on the new regulatory regime's understanding of "appropriate" modes and levels of protection for consumers across the range of financial services products, from theoretical, policy, and practice perspectives.

\section{Theoretical Framework}

Consumer protection is a primary motivation - and justification - for regulation of financial services. ${ }^{1}$ Consumers of financial services are regarded as needing greater protection than consumers of other types of goods and services, for a range of reasons. These include the amount of money that is at risk and the high possibility of principal-agent conflicts of interest. ${ }^{2}$ Financial services are often experience or "credence" goods, i.e., goods whose characteristics such as quality or price cannot be easily ascertained at the time of purchase. ${ }^{3}$ This, combined with the large amounts often involved, the long duration of many financial transactions, significant information asymmetry between buyers and sellers, as well as the industry incentive structures, is recognized as requiring regulatory intervention in financial markets in order to protect consumers. ${ }^{4}$

The global financial crisis of 2007-2009 provided the impetus for reflection on the extent to which the prevailing ideas about the implementation of consumer protection regulation are appropriate in achieving the desired outcome of adequate consumer protection. The crisis highlighted the problems that flowed from over-reliance on neo-classical approaches to consumer protection, based on the assumption of rational, informed consumers, equipped to safeguard their own interests in the market. Following the crisis, Martin Wheatley, the current head of the FCA, was clear in signalling that a new approach was needed: "The regulatory model had failed. The standard orthodoxy was that...people make rational decisions when given sufficient information: that markets are selfcorrecting and...that if you oversee the distribution channels - the right products get to the right people. All three orthodoxies failed." 5

The 2012 Act has purported to pave the way for a more nuanced approach to the protection of financial services consumers. This new approach is based on the idea that consumers are heterogeneous, with varying abilities and opportunities to protect themselves from sellers.

\footnotetext{
${ }^{1}$ *Dr. Folarin Akinbami is grateful for funding from the Leverhulme Trust (project: Tipping Points project). He would like to thank Professor Roman Tomasic, Professor Ranald Michie and his colleagues on the Tipping Points project. Professor Lorna Fox O'Mahony is grateful for funding from the Leverhulme Trust ('Mind the (Housing) Wealth Gap: Intergenerational Justice and Family Welfare, RP2011-IJ-024).

C. Mayer. (2001).Regulatory Principles and the Financial Services and Markets Act 2000. In E. Ferran and C. A. E. Goodhart (eds.), Regulating financial services and markets in the twenty first century. Oxford: Hart Publishing, at p.26.

2 Goodhart, C. A. E. (1998). Financial regulation: Why, how and where now. London: Routledge, (1998) at p.7.

${ }^{3}$ Nelson, P. (1970). Information and consumer behaviour. Journal of Political Economy, 78(2), 311-329.

${ }^{4}$ Ferran, E. (2012). The new mandate for the supervision of financial services conduct. Current legal problems, 65, 411-453, at p.413; Goodhart, C. A. E. (1998). Financial regulation: Why, how and where now. London: Routledge at p.7-8.

${ }^{5}$ Wheatley, M. (2012). My vision for the FCA. Available at www.fsa.gov.uk
} 
While information disclosure is still an important theme in consumer protection regulation, it is increasingly seen as a technique that should be used in conjunction with other techniques rather than a stand-alone solution. The new approach also signalled a shift in approach, from the dominance of point of sale regulation to an approach which incorporates greater use of $e x$ ante product and supplier regulation including intervention in the earlier stages of the design of the financial services products in order to ensure that the products are appropriate for their intended market.

In the 2011 White Paper, A new approach to financial regulation: Building a stronger system, HM Treasury described "appropriate" financial regulation as "reflect[ing] the fact that different consumers require different degrees of protection, depending on their capability and personal circumstances, the product they are buying, and the channel through which they are buying it" [4.17]. In recognizing the differentiation of the consumer population- "from retail customers choosing a current account to a hedge fund engaging in multi-million pound derivatives trades" [4.7] - the White Paper proposed a "fundamental shift in approach, particularly with respect to retail customers" [4.8], in which "the regulator may differentiate its approach according to the consumer in question..." [4.17]. The Government recognized the differentiated value of information for different consumer groups. Thus, while it might be reasonable to assume - for financial professionals or more financially capable customers - that "effective retail customer protection could be achieved by scrutinizing sales processes to make sure that customers were treated fairly and received appropriate and transparent information" [4.8]; the White Paper recognized that, for others, the focus on "point of sale" protections has proven to be insufficient. The White Paper went on to suggest that " $t \mathrm{t}]$ he FCA will therefore have a greater willingness to intervene in the early stages of the product lifecycle where appropriate to deliver better outcomes..." [4.8].

The theme of differentiated consumers is carried through in section $6(1)(1 \mathrm{C})$ of the Financial Services Act 2012, which defined the Financial Conduct Authority's "consumer protection objective" as "securing an appropriate degree of protection for consumers." In meeting this objective, the FCA must have regard to a range of differentiating factors, from differing levels of product risk (a) to variations in "consumer risk" - their experience, expertise (b), and expectations (f) of different products, as well as different needs for information and advice (c). The provider's responsibility is also recognized - through the requirement that they achieve an appropriate, contextualized level of care (e), while consumer responsibility remains a general principle (d).

In seeking to understand what this "range of differentiating factors" may mean for the FCA's approach to consumer populations, it is important to recognize that the "consumer protection objective" sits alongside operational objectives relating to the integrity of the UK financial system and the promotion of effective competition in the interests of consumers in the markets for regulated financial services and investment services. The competition objective also refers to "the needs of different consumers who use or may use those services, including their need for information that enables them to make informed choices" (section $6(1)(1 \mathrm{E})(2)(\mathrm{a}))$. Overarching this, the FCA's strategic objective of "ensuring that relevant markets function well" (section 6(1)(1B)(2)), through the three operational objectives that sit under it, were intended to "promote good outcomes for consumers, through a differentiated and proportionate approach which takes into consideration the knowledge and financial sophistication of the various types of consumer...."

${ }^{6}$ FSA. (2011). The financial conduct authority: Approach to regulation. London: Financial Services Authority, Para 1.11. 
The vehicle through which the FCA purports to achieve differentiated consumer protection is to "be more outward-looking and engaged with consumers than the FSA has been... and better informed about their concerns and behaviour where this is relevant to regulatory action." A true evaluation of the "appropriate" degree of protection for consumers clearly requires an understanding of (a) the nature of the consumer population (including for, or within, particular product markets) and (b) where their vulnerabilities lie in relation to these transactions.

Once the nature of the consumer population is understood, the nature of products and their effects on particular sections of the consumer population can also be better understood and regulatory interventions calibrated to achieve an "appropriate" level of consumer protection. One challenging issue in financial services regulation concerns the "one-size-fits-all" approach to products and services, particularly if these are designed for a standardized perfect customer and do not reflect the realities of contextualized decision-making, ${ }^{7}$ or respond to changes in circumstances. ${ }^{8}$

A more sophisticated understanding of vulnerability, together with regulatory regimes geared towards the needs of a differentiated consumer population, helps regulators, trade bodies, and firms to achieve more for consumers. The FCA defines a "vulnerable" consumer as someone who, due to their personal circumstances, is especially susceptible to detriment, particularly when a firm is not acting with appropriate levels of care. ${ }^{9}$ Most recently, the FCA has indicated its preparedness to adopt a broad conception of vulnerability — one which recognizes that the sources of vulnerability go beyond individuals' personal characteristics, to include a range of contextual factors. ${ }^{10}$ Furthermore, while some circumstances that cause vulnerability are longstanding, others may arise extrinsically, almost overnight, and could affect anyone distinct from level of income or capability. ${ }^{11}$

While the FCA's commitment to recognize the complexities of consumer vulnerability is welcome, the interaction between applications of the "cost-benefit analysis" framework, the identification of particular risks as "market failures," and the FCA's approach to proportionality is likely to remain crucial in determining the extent to which the FCA will be able to meaningfully achieve appropriate differentiation within the consumer protection objective. The 2011 White Paper emphasized that better outcomes must be pursued in a way that recognizes both the limits of regulation and the potentially negative effects of excessive regulation on market efficiency and consumer choice [4.9], and the Government emphasized concerns about the mounting cost of financial services regulation and questioned whether the benefits of many new regulations outweighed the costs. ${ }^{12}$

The FCA's commitment to consumer protection for the "differentiated consumer" must also be understood in the overarching framework of the FCA's strategic objective, to "ensure that relevant markets function well." The Government underlined the role of the "umbrella" objective in ensuring that the FCA would not be tempted to pursue any single operational objective in ways that undermine functioning of the market, for example, by removing all risk or dis-incentivizing improvements in product design. The Government therefore advocated a "balance in the pursuit of the operational objectives [with a] check...provided by the strategic objective."13 Some clues as to how that balance might be understood can be gleaned from the

\footnotetext{
${ }^{7}$ FCA. (2015). Consumer vulnerability. FCA Occasional Paper No. 8. London: Financial Conduct Authority, at p.43-44.

${ }^{8}$ ibid. at p.43-44.

9 ibid. at p.7.

${ }^{10}$ ibid. at p. 17 .

11 ibid. at p. 17 .

12 Twenty-eighth report of the Treasury Committee (2010-12). Financial Conduct Authority: Report on the government's response (HC 1857).

${ }_{13}$ Public Bill Committee (Bill 278), 2010-12, Financial Services Bill.
} 
FSA's Approach document, which clearly emphasized that the FCA would not aim to prevent all conduct failure, would not be an economic regulator in terms of pricing, and did not intend to provide kite-mark or product approval [3.23-3.28]. At the same time, the FCA should remain interested in prices to the extent that prices and margins can be key indicators of whether a market is competitive, whether customers are being fairly treated [p19, Box 2].

In this Special Issue, Peter Cartwright's "taxonomy of consumer vulnerability" explains how complex and multi-faceted the problem of vulnerability is and demonstrates the importance of understanding the sources and effects of vulnerability for different consumers. In mapping the field of consumer vulnerability, Cartwright seeks to understand the potential impact of various regulatory strategies for financial services transactions in terms of the types of vulnerability they seek to counter. For example, information disclosure - which, prior to the financial crisis, was the main approach to consumer protection - is depicted as a useful tool in protecting against information vulnerability, but with limited power to counter other sources of vulnerability for financial services consumers. Cartwright considers how the range of responses to consumer vulnerability, from product regulation, bans, and cooling off periods to improving redress and the use of open-textured standards such as the Unfair Commercial Practices Directive (UCPD) and the Treating Customers Fairly (TCF) initiative, can achieve the goal of protecting vulnerable consumers in balance with the other FCA's other objectives.

Sarah Nield focuses on the Mortgage Market Review (MMR) to explore the differentiation of mortgagors from other financial services consumers and to reflect on how this might be recognized in a differentiated approach to consumer protection. She argues that the homeowner's unique vulnerabilities to default and repossession require a tailored approach, which goes beyond the standard "market failure" rationale for regulation, drawing instead on a more nuanced idea of the "public interest." This argument is based on the unique nature of the mortgage contract as a long-term obligation where even the most stringent sales standards cannot eliminate unforeseen risks. With its overarching focus on front-end pre-emptive action to reduce the risk of mortgage default - through the sales process and by trying to ensure affordability of mortgage credit - the MMR signals a shift towards placing more responsibility on mortgage providers to protect borrowers from irrational borrowing decisions. Nield identifies the weaknesses of this strategy, which, while effect in identifying borrowers who are particularly vulnerable (e.g., first-time buyers and credit-impaired borrowers), does not do enough to protect them. Although the MMR potentially provides more protection at the front end of the transaction (i.e., at the point of sale), Nield argues that it does not do enough to help the borrower later in the credit relationship, i.e., if the borrower's circumstances change or the borrower becomes faced with the prospect of default, and so represented a missed opportunity to consider how particular classes of vulnerable borrowers might be treated in the event of default. Finally, Nield argues that, in light of policymakers' focus on mortgage-financed homeownership, not enough is being done to help borrowers transition to other housing alternatives when homeownership is no longer sustainable.

Lisa Whitehouse's article problematizes the conceptualization of the first legal mortgagor in land law (with its origins in private law) - as a rational contracting party to a commercial transaction or a knowledgeable consumer able to bargain with lenders. Whitehouse argues that this belies the true nature of the mortgagor and is inconsistent with the conceptualization of the borrower in financial services regulation (which has its origins in public law) - as someone in need of consumer protection vis-à-vis their credit relationship with more knowledgeable, more powerful (often institutional) lenders. Whitehouse argues that the continued operation of two distinct regulatory regimes (land law and financial regulation) - founded on different 
conceptions of the mortgagor - to govern this transaction inhibits attempts to create a robust regulatory framework that ensures that all mortgagors are adequately protected. She proposes a unified approach, whereby both land law and financial regulation conceptualize the mortgagor as a consumer is what is needed. This would also equate certain aspects of the purchase of land with the purchase of other products, so reversing the ironic situation whereby mortgagors receive less protection than consumers purchasing non-essential goods. This is a powerful argument, which echoes the justifications for the creation of the US Consumer Financial Protection Bureau (CFPB). ${ }^{14}$ Whitehouse argues that the mortgagor under a first legal mortgage deserves special attention and tailored regulation, particularly during the possession process. This is premised on the special and unique characteristics of the mortgage, whereby the borrower focuses on the asset purchased rather than the financial services product, i.e., the loan-leaving the mortgagor is less likely to be aware of the content and consequences of the mortgage contract - and the fact that the first legal mortgage facilitates the acquisition of a "home" rather than a mere commodity. Whitehouse argues that the current reform of financial services regulation provides an opportune moment to initiate a fundamental shift in the legal conception of the mortgagor.

Finally, Andrea Fejos uses the recent reforms to the regulation of high-cost short-term credit (payday loans) to demonstrate the potential that product regulation, tailored to specific consumer sub-populations, can have in protecting vulnerable consumers. She explains the FCA's new product regulation power, which is the basis for much of its payday loan regulation. She justifies the use of product regulation on the basis that payday loans are an area where targeted product regulation is necessary because the problems inherent in payday loans cannot be resolved by market forces alone. She also explains the characteristics and particular vulnerabilities of those consumers who tend to use payday loans and sets out the reasons why such loans are problematic. Although there is some diversity among the different types of payday loan users, they all share the common features of either low income or high pre-existing indebtedness, and are thus less resilient to income and expenditure shocks. Fejos also explains the particular features that make payday loans problematic, i.e., their high cost and the availability of the "roll-over" facility. Yet, she argues that, despite the problems associated with payday loans, an outright ban on the product would not have been appropriate as they also convey some important benefits. Rather, a more nuanced approach was needed, and this is what the FCA has achieved through product regulation. The new specialist sourcebook containing the rules regarding the provision of consumer credit (CONC) enhances the responsible lending regime so that greater responsibility is placed on lenders to provide credit only where it is appropriate, i.e., where the borrower is capable of repaying it without getting into financial difficulties. In addition, the targeted nature of the new product regulation regime means that it is better placed address the unique problems inherent in payday loans, i.e., the "roll-over" feature and excessively high interest rates and fees charged. In sum, the new interventionist, consumer-centric approach adopted by the FCA has a better chance of dealing with the problem of payday loans than the less intrusive, market-based approach adopted by the FCA's predecessors or by any blanket ban on payday loans. Regulation of payday loans therefore provides a good example of a nuanced approach towards a particular product that adversely affects a particular sub-population of financial services consumers.

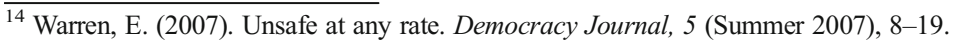




\section{Conclusion}

While the impact of the 2012 Act in framing a new approach to consumer protection under the FCA remains to be fully revealed, this issue seeks to offer some insights to the potential that the new framework offers for the FCA to deliver "appropriate consumer protection" across a range of retail financial services sectors. A crucial aspect of "appropriate consumer protection" is that it is rooted in an understanding of consumer populations, built upon accurate and realistic conceptualizations of "the (differentiated) consumer," across and within market sectors. The Mortgage Market Review demonstrated some of the ways in which regulatory protections can be nuanced to the needs of differentiated consumers, from the identification of "high-asset consumers" as a sub-set of the consumer population requiring - and indeed, preferring, in exchange for lower prices - less regulatory protection to the designation of other categories of consumer (e.g., consumers of higher-risk products (for example, equity release, sale and rent back, and right to buy customers) ${ }^{15}$ and higher-risk consumers (the highest-risk consumer is deemed to be one who is borrowing to consolidate existing debt). ${ }^{16}$ Cartwright's taxonomy of vulnerability offers a valuable frame in which to test how we relate the nature of consumer vulnerabilities, in specific sectors and circumstances, to regulatory responses, while Fejos' analysis of the regulation of payday loans demonstrates the capacity for the FCA to develop a carefully calibrated approach to regulation that goes beyond the information paradigm to develop an appropriately nuanced approach to regulation. It is still early days for the FCA, with plenty of consumer protection challenges ahead. This Special Issue aims to support the evolution of the "differentiated" approach to consumer protection in financial services regulation, by reflecting on benefits of tailored financial services regulation drawing from across the regulatory "tool kit" to address the different needs and vulnerabilities of consumer populations.

\footnotetext{
${ }^{15}$ FSA. (2009). Mortgage market review. London: Financial Services Authority. Available at http://www.fsa.gov.uk/ pubs/discussion/dp09_03.pdf; FSA. (2011). Mortgage market review: proposed package of reforms (CP11/31), para 5. 77. Available at www.fsa.gov.uk/library/policy/cp/2011/11_31.shtml.

${ }^{16}$ ibid. para 5.86 .
} 